\title{
7. THE COMPLEXITY OF REPRESENTATIONS IN THE CHEMISTRY TEACHING: AN EXPERIENCE FOR ATOMIC MODEL
}

\author{
Maria Fernanda Moreira, Agnaldo Arroio \\ Faculty of Education, University of Sao Paulo, Sao Paulo, \\ Brazil
}

\begin{abstract}
This work presents a portrait of research in chemistry education addressing the problematic of the representation on chemical knowledge, interpreting them in an experimental framework that relates not only the complexity in the choice of materials, as well as the difficulties and methods. It was concluded that there is a need for a coherent pre selection of teaching materials to be used, and also that education based on visual aids and models need to be extensive, covering not just isolated events.
\end{abstract}

Key words: modeling; representation of chemical knowledge; teaching of chemistry; visualizations.

\section{Introduction}

The teaching based on visualizations and modeling has become, in recent years, one of the focuses on the discussions to improve the learning of scientific concepts in high school and also at the university (Nersessian, 1995; Devi et al., 1996; Sutton, 1996; Greca and Moreira, 2002; Justi and Gilbert, 2002). Could be indicated, in other respects noted in the highly varied and abundant literature that was found on the subject, at least two sources that apparently generate some type of confusion: on one hand, in some situations there is an almost complete identification of models with analogies created by the professor, and in the other, the use of theoretical frameworks from the psychology of cognition (the mental processes that are acting behind human behavior). This area of research encompasses several areas, examples include questions on memory, attention, perception, knowledge representation, reasoning, creativity and problem solving, and with them the terminology of representations and mental models gives rise to another polysemic focus when related with the models and representations of chemistry.

Harrison and Treagust (2000) used in their texts the idea of an analogous model as a way to represent both family entities, often daily and pretty well known to students, but also as the unobservable. The terminology, which means, the study of analogue models, is used because the model could also be considered as a way to do something. In the case of chemistry, analog models may be particularly: scale models, molecular models, iconic symbolic models (a chemical formula), mathematical models, theoretical models (mechanisms reaction), and models of concepts (models of acids, bases and redox) among many others. But how is it possible for a student to understand how an analogy or even a chemical reaction when it is not intended to represent a phenomenon, but to describe an operat- 
ing mechanism or a process without tangibility that macroscopic world provides us? Is it then launched the biggest challenge with regard to the use of modeling as an ally in natural science education and especially here, in the case of chemistry.

The idea that comes from models used for analogies, are also extremely difficult to apply not only in chemistry, but in other disciplines that have this feature that brings the human being a sense of awkwardness and vulnerability of the intangible, remarkable feature of sciences of the nature. These proposals include both questions correlated to semantics as the underlying mathematical models. Those scientific models serve as a bridge between the real world (complex and holistic) and an idealized world (abstract), existing only in the world of scientists. This simplified model preserves the essential characteristics of the system or phenomenon that is intended to describe, explain or predict. Which analogies could we use to describe the behavior of the fundamental particles? How to insert the veracity of such particles to students?

All of these matters that delimit our representations are constructed and developed from our macroscopic livings, which no doubt will conflict with the principles that govern the world we can not experience, much less contemplate with our eyes. What is observed of chemistry in our reality, is mostly just a mere consequence of that which is not possible to actually measure in our reality and what actually is being investigated, that is, the causes are another level views.

These issues could also be found in Arthur Miller (cited Yamalidou, 2001), where it can draw from their research the huge role of the mental image created by the students (and often by teachers, without a shadow of doubts have also been students) in the formulation of scientific theories in the next few centuries, where he just says that ,the analogies can not be built in situations beyond the limit of our pictorial representation."

Taking into account Verloop and Driel (1999, p. 1142) was placed that a model has certain similarities with the objective, can be thought of as ,a search tool that is used to obtain information about a goal that can not be observed or measured directly". This idea that is being presented broadcasts a definition of modeling that can hardly be applied to models in the disciplines of chemistry and physics. Taking as an example, the model of the rigid body, often used in classical physics, thus able study the behavior of objects in our world palpable, that is, which have the macroscopic character, can not be said that the modeled objects can not be observed or measures the important variables directly. We can say that they simplify the phenomenon that is being studied, but it is of the utmost importance to emphasize here that one can not limit the concept of model about not only what can't be seen, touched or directly measured. This also happened in the history of chemistry, whose great tradition has always been centered on what can be measured. For example, the study of the atom in eighteenth-century is part of an experimental program of arithmetic characterization, that is, which sought to determine the measurements of each substance (Dumas, 1837 quoted in Bensaude-Vincent and Stengers, 1992).

According to Gilbert et al. (1998) all models are formed by a process that deconstructs the analogies. An idea that is widespread in the teaching of chemistry and also in Science. On the one hand, the authors who have been consulted always express an idea more acceptable than one that simply identifies analogies with models. In this sense, use analogies as a mechanism for the development of theories or models is different to equal- 
ize the analogies with the results of the modeling process. That is, it is not correct methodologically match each other.

The relationship established between reality and the physical model is said to be of great complexity, so that when it comes to ,visualizations“ these have to be understood in a dilated way and not only as a relation of the imagination, where each element of the model corresponds to a element of reality. As pointed out by Dirac (quoted in Jammer, 1974, p. 13),"though the main purpose of science is not the supply of images, and the fact that they exist or not be a matter of secondary importance, one can always understand the meaning of the word image to include any way to see the fundamental laws that become apparent self consistency". The physical and chemical theories belonging to our last century, have restricted its use with regard to views, this can be meant in part, as stated earlier, due to limitations of the representations that we generate from our everyday experience and therefore our macroscopic experience.

\section{Methodology of Research}

This proposal was applied to second year of the high school with two groups, the room „B“" was the experimental group and the room , $\mathrm{A}$ “ was the control and only a written assessment test was the same. For the room B, experimental group, it was determined that in addition to an explanation expository addressed in PowerPoint, students still count with two different tools of aid methodology in the classroom, the „Phet“, which is a website of pedagogical simulators developed by the University of Colorado which can be found available on the Internet (Interactive Simulations: University of Colorado), in addition to there is a video that has the same methodological approach. The room A, control group, would contain only two classes in PowerPoint lecture method, without applying any of the tools described above, by the way the theme of this proposal was Atomic model.

\section{Implementation of Activities Room B}

The class was introduced with a PowerPoint presentation, in which all atomic models were presented descriptively and textual, so that students have a broad overview of the development of atomic postulates that occurred during the growth of theories. After the theoretical explanation, were also presented to students two software „Phet", the first entitled „Build an atom.“ The simulator was necessary to improve the class for a better visualization of concepts such as mass number, atomic number, symbol of the elements and the reason between the differences of an atom of a chemical element to another. The software presents the possibility of adding a significant number of combinations of protons, neutrons and electrons to check if the atom is presented in a neutral way (without being a cation or an anion) or even if this representation built in the classroom is a stable representation. 


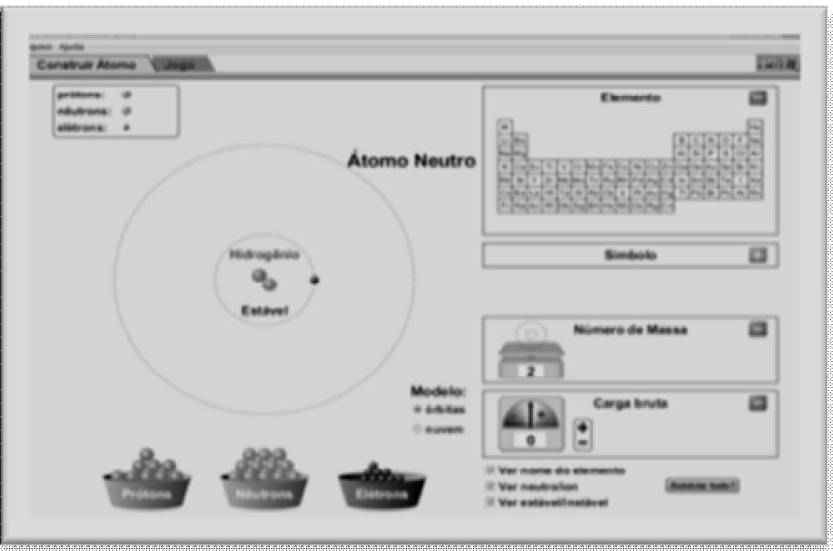

Figure 1. Representation of the Hydrogen atom stable

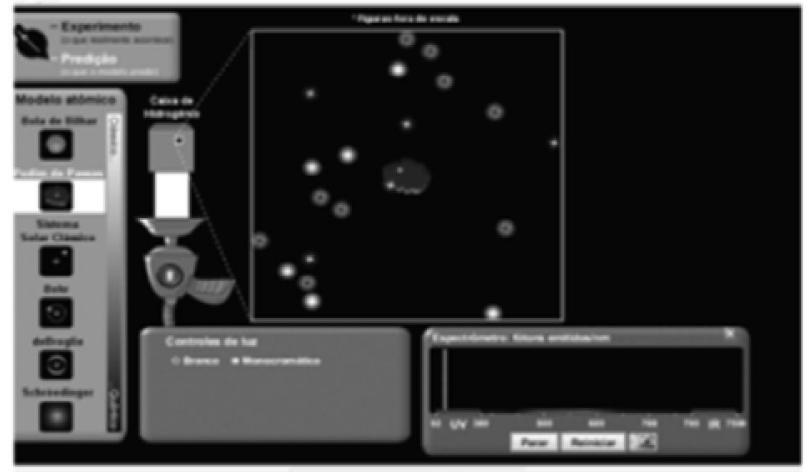

Figure 2. J. J. Thompson Atomic Model representation with the emitted particles undergoing bypass.

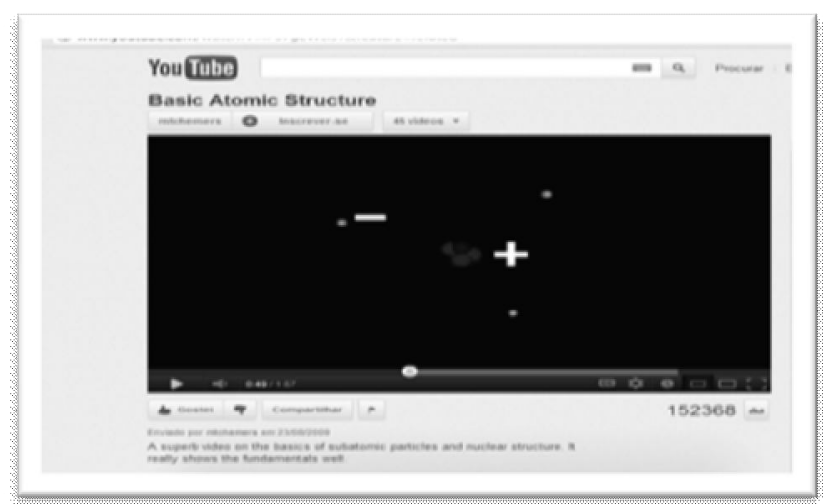

Figure 3. Representative video regarding atomic models
The second simulator is entitled "Model of the Hydrogen Atom" in which there is a representation of all atomic models that were presented during class (Dalton Model, J. J. Thompson model, model of Rutherford and Bohr Model) is a simulator that demonstrates the difference of representations through the radiation of subatomic particles like protons, neutrons and electrons through the model of the atom and the consequence of such behavior. The simulator is made of great value for a better visualization of dynamic models by students and clear disclosure of the difference between the postulates.

After the presentation of these two simulators a discussion was done about everything that had been placed for the students and the first part of the class was finished. In a second phase, which was held in a separate class, it was remembered what had done in the last meeting and then presented the educational video that would be reviewed and used for the fostering further discussion regarding the program content of atomic models.

The chosen video to finalize the theme was taken from the website youtube.com entitled „Basic 
Atomic Structure," in which there is a preview of how the sub-particles are arranged in a possible atomic model, a potential representative characterization of why do these micro particles remain aggregated within the atomic models and an explanation of the electronic behavior.

After the video exhibited, students could discuss about their doubts and also all the content of these classes were recovered. Before, a test was applied to evaluate the activities, annex A. It was employed a qualitative analyses and a content analyses (Bardin, 2010) for open question.

\section{Results of the Research}

For the correction of the activities, were assembled two charts based on answers given by the students and that are related to each question individually. For graphic approaches were assigned percentages based on the following criteria:

- Settlements total issue;

- Setting-half of the question;

- Settlements of less than half of the question;

- No settlement reached in the matter.

\section{$\underline{1 \text { st Question }}$}

Room A

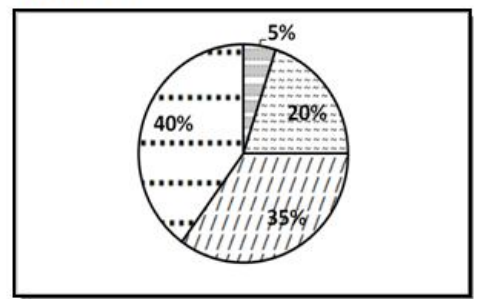

Room B

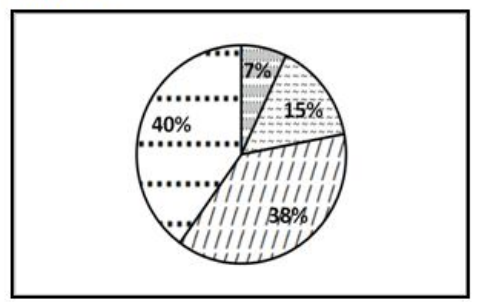

Legend: $35 \%$ of students correctly answered the whole question. $40 \%$ correctly answered half question. $20 \%$ of the students answered less than half of it.

$5 \%$ did not hit any items.

Legend: $38 \%$ of students correctly answered the whole question. $40 \%$ correctly answered half question. $15 \%$ of the students answered less than half of the exercise.

$7 \%$ did not hit any items. 


\section{2nd Question:}

Room $A$

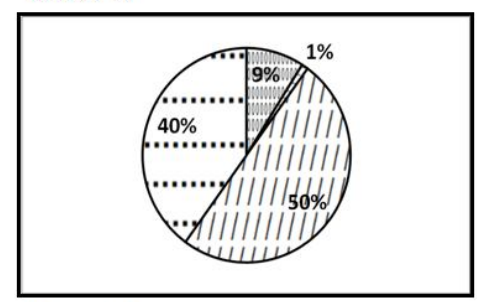

Room B

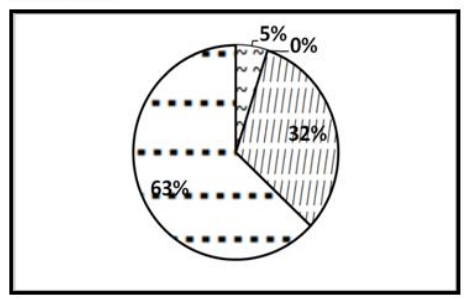

Legend: $40 \%$ of students correctly answered the whole question.

$50 \%$ correctly answered half question.

$9 \%$ of the students answered less than half of the exercise

$1 \%$ did not hit any items.

Legend: $32 \%$ of students correctly answered the whole question.

$63 \%$ correctly answered half question.

$5 \%$ of the students answered less than half of the exercise.

$0 \%$ did not hit any items.

\section{3rd Question:}

Room $A$

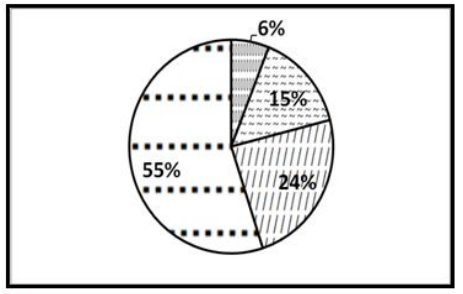

Room B

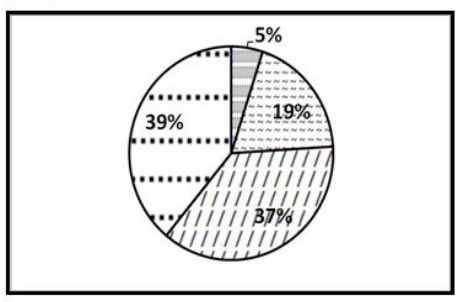

Legend: $24 \%$ of students correctly answered the whole question.

$55 \%$ correctly answered half question.

$15 \%$ of the students answered less than half of the exercise.

$6 \%$ did not hit any items.

\section{Room A}

Legend: $37 \%$ of students correctly answered the whole question. $39 \%$ correctly answered half question. $19 \%$ of the students answered less than half of the exercise. $5 \%$ did not hit any items. 


\section{4th Question}

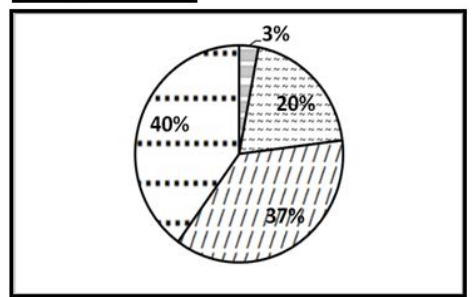

Room B

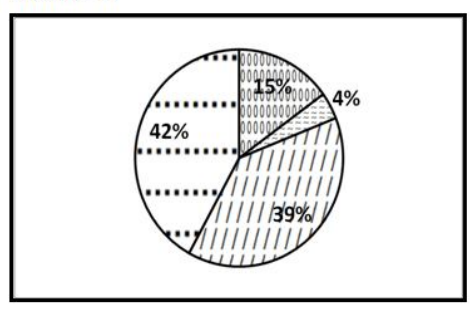

\section{5th Question}

\section{Room A}

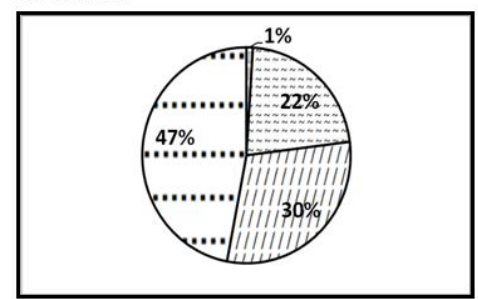

\section{Room B}

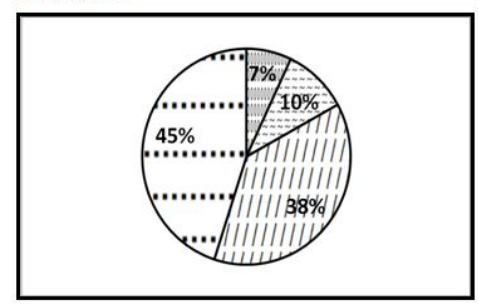

Legend: $37 \%$ of students correctly answered the whole question.

$40 \%$ correctly answered half question. $20 \%$ of the students answered less than half of the exercise.

$3 \%$ did not hit any items.

Legend: $39 \%$ of students correctly answered the whole question.

$42 \%$ correctly answered half question.

$15 \%$ of the students answered less than half of the exercise.

$4 \%$ did not hit any items.

Legend: $30 \%$ of students correctly answered the whole question.

$47 \%$ correctly answered half question. $22 \%$ of the students answered less than half of the exercise.

$1 \%$ did not hit any items.

Legend: $38 \%$ of students correctly answered the whole question.

$45 \%$ correctly answered half question.

$10 \%$ of the students answered less than half of the exercise.

$7 \%$ did not hit any items.

\section{Room A and B}

There was a greater number of hits referring to the control room in the question 1, that initiated the thread, objective justification that also it is valid to the fact that the question of the beginning approached concepts purely theoretical, that just makes sure that the students were memorizing and in a way, reproducing, what was work in the classroom. But the idealization of the atomic models existed, which could clear the little difference of only $3 \%$ between classes $\mathrm{A}$ and $\mathrm{B}$. 
For 2nd, 3rd, 4th and 5th questions, the exercises showed that the room B had a higher rate of responses that include expectations related, because it dealt with issues that quite possibly the simulators used of Phet had great value, due to the active participation of students in activities that relate to idealizations microscopic theoretical issues embedded in them. Although there is an apparent disclosure of a positive result, the indices indicate a small margin of advantage, that is the percentages were not as widely significant.

\section{Discussion}

The Results that stress the research have already highlighted the work of Van Driel and Verloop (1999), where can one find the importance of learning tools for content where there is not the possibility of observations and measurements to be made directly. Similarly to the first question, the percentage of correct discrepancy became very low, an average of approximately $10 \%$ difference in the responses within the expected years between A and B. Results of research mentioned by Allie et al. (1998) show that students have greater application in terms of skills and conceptual construction when, rather than following a list of instructions and just watch a conceptual explanation, as it is usually proposed, understand the procedures of trial and participate in the proposed activities. From this, the author argues that this understanding depends on the context and form of how activities are performed by students, that is, how and in what level was the engagement of students during the exercise suggested, which highlights the matter of despite the percentage was small, there was an improvement on the understanding of the subject by students who had more contact with it through the supplementary activities.

The conclusion can be detached by Berg et al. (2003) that converge to this line of thought to note better results on learning in the form of open experimentation, encouraging reflection, questioning and allows a more accurate understanding of the concepts involved.

\section{Interview with Students Involved in the Activities.}

Weeks after to the sequential design, installation, implementation, measurement and reading of data obtained regarding the activities intended and performed throughout the process, was also important to see through the prism of collegiate impressions filed through the process. To this end, it was schedule an „Interview with Students involved in activities" for students from room A and B.

During the interview were asked topics as students' views on the methods used, and in particular about the video and simulators, in relation to student achievement with respect to activities and analysis of the overall picture, that is, students' views, the action was significant or not.

Most of the students said to have a greater affinity with the simulators, which coincides with the research of Berg et al. (2003) and Arthur Miller. According to themselves, the computer programs used gave a greater autonomy, not only for learning in the classroom, many students revealed that, in their homes, they have accessed the website that has content and redid the experiments comprehended in the classroom, many even effected in different ways, discovering new tools, trivia or new methods of reaching to the same result, showing a positive factor to deal with interactive computer programs for a genera- 
tion so innately familiar with new technologies. The videos have not prompted much interest from college, many noted that other teachers have been widely used this resource and that the videos are often accompanied by concepts that students do not have or do not need to possess, and that teachers do not make a pre or a cut-selection of these spare parts to program content, that is, as amply demonstrated in the literature (eg. Arthur cited Yamalidou Miller, 2001) there is a necessity of a pre-selection and editing the material to be worked with the students to that views only add and not hinder the pedagogical development of the student.

\section{Conclusions}

During the work, focusing on the complexity of representations in chemistry teaching, carried out with students of second year of high school, it was possible to analyze a real intrinsic difficulty of observation as regards the imaginative limit imposed by teachers. Often analogies created by high school teachers, for the representation of several subunits of chemistry teaching, they become somehow more intangible than the subject addressed itself and makes it even more tenuous and complex fixing coherent knowledge that is being worked on. It was noted that perhaps the short time of work with the students, or the lack of assimilation of new practices, both in relation to teachers and learners with matching, or even the complexity of the wearing and use of such tools for teaching, there was a little variation, although present, in academic achievement, with respect to the parts of the discipline that have been applied.

But perhaps the most significant of the proposed work is the actual fact of a possible opening of the education system and wider distribution for multiple visions of the future of teaching practices and an increased introduction of intangibles in school environments. It became evident through the analysis of the whole; the paramount need to work cautiously with visualizations for teaching, there is a great advantage in its use, especially in the long term, that is, if the method is implemented for all students. But in consequence of the wide range of information and materials available nowadays, mainly through the exponential rise of the Internet, there is the prediction of teaching to have a filter in relation to such information that will be incorporated, so that the analogies, views or modeling fulfill their done and not make education even more complex and full of insurmountable barriers to learners.

\section{Materials Used}

Interactive Simulations: University of Colorado. „Build an atom.“ Available at: $<$ http://phet.colorado.edu/pt_BR/simulation/build-an-atom>. Accessed on 5 April 2012.

Interactive Simulations: University of Colorado. „Model of a Hydrogen atom.“ Available at: <http://phet.colorado.edu/pt_BR/simulation/build-an-atom>. Accessed on 5 April 2012.

LABORATORY OF CHEMICAL EDUCATION AND LEARNING - UFSCAR. „Physical States of Matter" Available at: <http://www.youtube.com/watch?v=RfHKr AdT8cQ $>$. Accessed on 5 April 2012.

„Basic Atom Structure“ Available at: <http://www.youtube.com/watch?v= 1P57gEWcisY>. Accessed on 5 April 2012. 


\section{References}

Allie, S., \& Buffler, A. (1998). A course in tools and procedures for Physics 1, American Journal of Physics, 66 (7), 613-624.

Bardin, L. (2010). Análise de Conteúdo. $5^{a}$ edição. Lisboa, Portugal: Edições 70, 2010. 281p.

Bensaude-Vincent, B., Stengers, I. (1992). História da Química. Lisboa: Instituto Piaget: Lisboa, p. 164, 176-177.

Berg, C. A. R., Bergendahl, V. C. B., Lundberg, B. K. S., \& Tibell, L. A. E. (2003). Benefiting from an open-ended experiment? A comparison of attitudes to, and outcomes of, an expository versus an open-inquiry version of the same experiment. International Journal of Science Education, 25 (3), 351-372.

Devi, R., Tiberghien, A., Baker, M., \& Brna, P. (1996). Modeling students' construction of energy models in physics. Instructional Science, 24, 259-293.

Gilbert, J. K., Boulter, C. J. (1998). Aprendendo ciências através de modelos e modelagem. In: Colinvaux, D. (Org). Modelos e educação em ciências. Rio de Janeiro: Ravil, p. 12-34.

Greca, I. M., Moreira, M. A., \& Herscovitz, V. E. (2001). Uma proposta para o ensino de Mecânica Quântica. Revista Brasileira de Ensino de Física, 1 (23), 444-457.

Greca, I. M., \& Moreira, M. A. (2001). Uma revisão da literatura sobre estudos relativosao ensino de Mecânica Quântica Indrodutória. Investigações em Ensino de Ciências, 6 (1), $1-29$.

Greca, I., \& Moreira, M. (2002). Mental models, physical models and mathematical models in the teaching and learning of physics. Science Education, 86, 106-121

Greca, I. M., \& Herscovitz, V. E. (2002). Construyendo significados en mecánicacuántica: fundamentación y resultados de una propuesta innovadora para su introducciónen el nivel universitario. Enseñanza de las Ciencias, 20 (2), 327-338.

Harrison, A., \& Treagust, D. (2000). Learning about atoms, molecules, and chemical bonds: a case study of multiple-model use in grade 11 Chemistry. Science Education, 84, 352381.

Jammer, M. (1974). The philosophy of quantum mechanics. New York: John Wiley \& Sons.

Justi, R., \& Gilbert, J. (2002). Modelling, teachers' views on the nature of modelling, and implications for the education of models. International Journal of Science Education, 24 (4), 369-387.

Nersessian, N. (1992). How do scientists think? Capturing the dynamics of conceptual change in Science. Cognitive Models of Science vol. XV. Minneapolis: University of Minnesota Press. Minneapolis. pp. 3-44.

Nersessian, N. (1995). Should physicists preach what they practice? Science \& Education, 4, 203-226.

Sutton, C. (1996). The scientific model as a form of speech. In. Welford, Osborne \& Scott (Eds) Research in Science Education in Europe. London: The Falmer Press Group.

Van Driel, J., \& Verloop, N. (1999). Teachers' knowledge of models and modelling in science. International Journal of Science Education, 21 (11), 1141-1153.

Yamalidou, M. (2001). Molecular Representations: building tentative links between the history of science and the study of cognition. Science \& Education, 10, 423-451. 


\section{Applied test}

1. Consider the atomic models of:

I. Dalton II. Thomson III. Rutherford

a) Which has been proposed based on the results of measurements of the masses of the participants in chemical reactions?

b) What entered the electrical nature of matter?

c) What presents matter as discontinuous?

d) Which is the most recent?

2. The silicon, the most abundant chemical element in nature after oxygen has great application in the electronics industry. In addition, sulfur is of paramount importance in obtaining the sulfuric acid. Knowing that the atom $5 t_{\mathbf{1 4}}^{28}$ is an ISOTOPE of a variety of isotopes of sulfur, $S_{16}$ it can be stated that this atom has number of mass equal to?

3. Sodium and its compounds, under certain conditions, emit a yellow light characteristic. Explain this phenomenon

4. An atom whose electron configuration ends in $4 s^{2}$, determine the atomic number and the number of energy levels.

5. Rutherford's experience has highlighted that the model of Thompson was correct? Explain.

Received 20 July 2012; accepted 03 September 2012

\begin{tabular}{|c|c|}
\hline $\begin{array}{l}\text { Maria Fernanda Moreira } \\
\text { Pre-service chemistry teacher, University of } \\
\text { São Paulo, São Paulo, Brazil } \\
\text { E-mail: } \underline{\text { maria.fernanda.moreira@usp.br }} \\
\text { Website: } \underline{\text { http://www.usp.br }}\end{array}$ & $\begin{array}{l}\text { Agnaldo Arroio } \\
\text { AhD, Associate Professor, University of Sao Paulo, } \\
\text { Faculty of Education, Av. da Universidade 308, blo- } \\
\text { co A, sala 109., Butantã, 05508-040 São Paulo - SP } \\
\text { - Brazil } \\
\text { E-mail: agnaldoarroio@yahoo.com } \\
\text { Website: } \underline{\text { http://usp-br.academia.edu/AgnaldoArroio }}\end{array}$ \\
\hline
\end{tabular}

